\title{
The emerging breast cancer epidemic: early diagnosis and treatment
}

\author{
Anthony Howell*
}

\section{Introduction}

Breast cancer is the most common malignant tumour in women. Estimates for 2008 indicate that 1.38 million women were diagnosed and 0.46 million died from the disease worldwide [1]. Currently, the incidence in the developed and developing world is similar but, whereas incidence rates are tending to plateau or decline in the West, they are increasing in the developing world, presumably related to changes in dietary and reproductive behaviours and ageing populations [1]. Total mortality from breast cancer is already higher in the developing world [1]. Whilst mortality is declining in most western countries, it is estimated that it will increase by over $100 \%$ in developing countries by 2020 [2].

Whereas less than one-third of women diagnosed with breast cancer in developed countries die from the disease, this proportion reaches over two-thirds in developing countries and is directly related to income per capita (Figure 1a) [1,3]. Berry and colleagues [4] developed a series of independent statistical models of breast cancer incidence in order to determine the relative importance of the contribution of mammographic screening and adjuvant therapy to the marked decline in breast cancer mortality in the majority of developed countries. They estimated the mortality decline was related equally to screening and therapy and that mortality would increase in countries with limited facilities for screening and treatment (Figure 1b).

\section{Early detection}

The analyses of Berry and colleagues and trials of screening indicate the importance of early detection by mammography. However, where mammographic screening is introduced into a country gradually, improvements in outcome are also seen in the non-screened group, which may, in part, be related to a general increase in awareness

*Correspondence: Anthony.Howell@christie.nhs.uk Breakthrough Breast Cancer Research Unit, Paterson Institute for Cancer Research, School of Cancer, Enabling Science and Technology, University of Manchester, Wilmslow Road, Manchester, M20 4BX, UK of the importance of early treatment [5,6]. Whilst randomised trials of breast self-examination versus no examination do not demonstrate the effectiveness of the intervention compared with women simply being made aware of breast examination [7], these studies do not address the issue of lack of awareness or of barriers to women presenting early rather than late. In many developing countries, the introduction of mammographic screening is currently not possible because of expense, the relatively low incidence of breast cancer and low age of diagnosis. Thus, the Early Resource Allocation Panel of the Breast Health Global Initiative (BHGI) produced guidelines suggesting a graded system of introduction for breast awareness and mammography based on whether the health care system was basic, limited, enhanced or maximal $[8,9]$. In countries with basic and limited resources they suggest the widespread introduction of culturally sensitive, linguistically appropriate, local education programmes to teach breast health awareness and awareness with mammography in countries with enhanced or maximal health care systems. An example is the Mumbai area in India, where mammography is not available but with education in the city two-thirds of women present with stage I and II breast cancer compared to only one-third in local rural populations (R Badwe, personal communication).

\section{Less than optimal treatment}

The difficulties associated with the introduction of optimal treatment for breast cancer, as defined by western standards, are highlighted by the absence or low distribution of radiotherapy and systemic therapy services in the developing world. In Africa, for example, radiotherapy services were available in only 17 of 44 countries surveyed [10]. The BHGI guidelines for the introduction of radiation therapy suggest use of cheaper and simpler cobalt machines compared with linear accelerators or shorter schedules. The Programme for Action for Cancer Therapy has introduced over 400 programmes to help introduce cancer and, more specifically, radiotherapy services in the developing world [11]. The BHGI has also issued guidelines for the introduction and evaluation of local and systemic therapies in relation to resources. For 

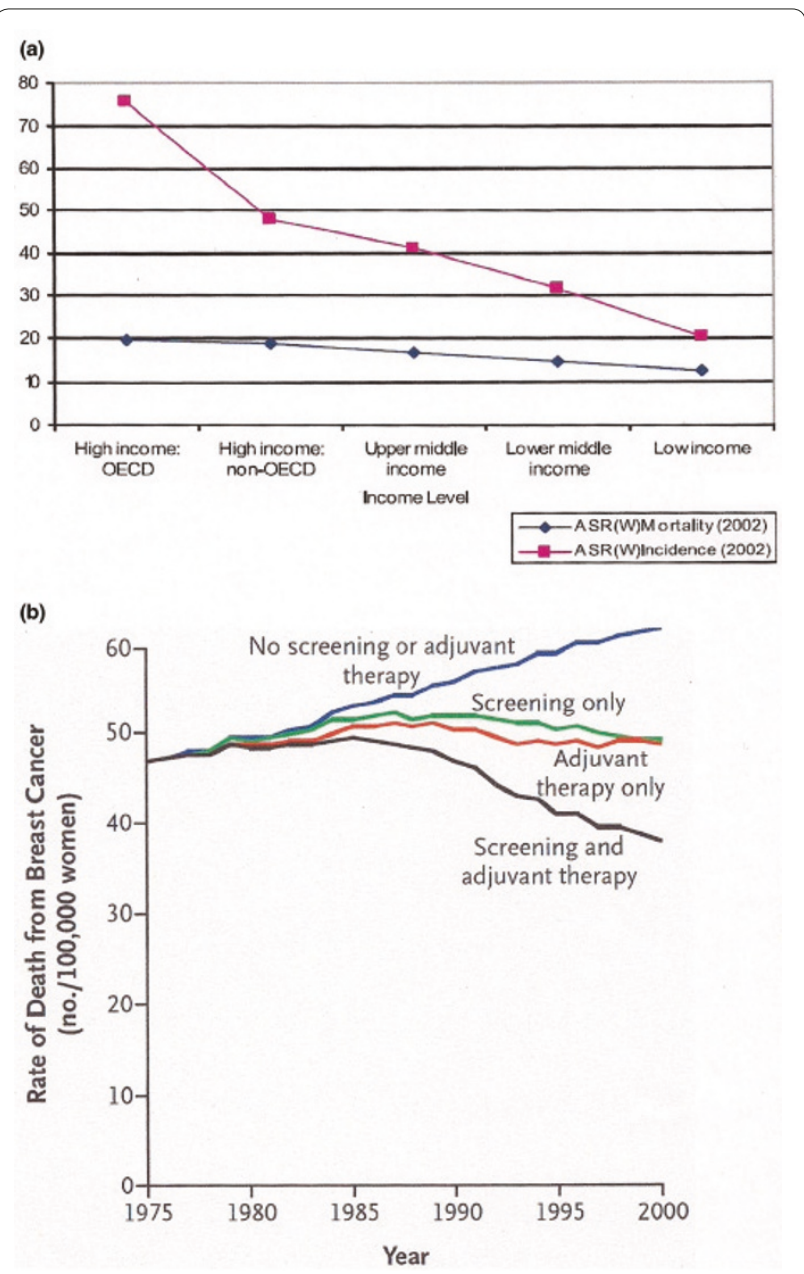

Figure 1. More deaths from breast cancer in the absence of early diagnosis and systemic treatment. (a) Income differences and differences between age-adjusted incidence and mortality (from [3] with permission). (b) Model of the estimates of the contribution of mammographic screening and systemic adjuvant therapy to the decline of mortality from breast cancer in developed countries and the effect of absence of both modalities (from [4] with permission).

example, in stage II breast cancer, for the basic level, they recommend radical mastectomy without radiation therapy and simple systemic treatment such as CMF (cyclophosphamide, methotrexate and fluorouracil) chemotherapy and tamoxifen (oophorectomy in premenopausal women) [12].

Questions arise concerning the affordability of treatment, particularly long-term systemic treatment. Affordability may be defined as the number of days' wages required for the lowest paid government worker to purchase a 1-month supply of treatment. Taking blood pressure treatment with aspirin, atenolol, an angiotensinconverting-enzyme inhibitor and a statin as an example, Mendis and colleagues $[13,14]$ calculated that treatment costs per month would take 5.4 days of salary for a middle income country such as Pakistan and 18.4 days for a low income country such as Malawi. Certain important but expensive treatments, such as herceptin, are simply not affordable in developing countries [15]. Such problems may be circumvented by introducing shorter treatment durations, intermittent treatments, differential pricing schemes and the use of low cost medicines, including generics, and, unfortunately, stratifying treatment options by available resources as suggested in BHGI guidelines [16]. Another approach is to test completely new low cost treatments. For example, Badwe and colleagues [17], based on information that primary breast operations in the luteal phase of the menstrual cycle improved outcome in their previous studies, demonstrated that a single injection of hydroxyprogesterone $(500 \mathrm{mg}) 4$ to 14 days preoperatively improved overall 5 -year survival in women with node-positive disease by an absolute value of $8.9 \%$. Another approach is to use relatively low cost approaches to predicting the necessity for treatments overall. For example, Cuzick and colleagues [18] demonstrated that a formula based on immunochemical estimation of oestrogen and progesterone receptors, HER2 and Ki67 with clinical features was as predictive as the Oncotype DX and potentially much cheaper.

\section{Conclusion}

There is little doubt that because of demographic changes and lack of access to early diagnosis and treatment in the developing world there will be continuous marked increases in the incidence of and mortality from breast cancer. It is crucial that there is a widespread increase in educational programmes to increase awareness and early presentation and the introduction of screening where affordable. The BHGI guidelines $[8,9,11,16]$ are useful indicators for governments of the potential sequence of developments for early detection and treatment. It appears, to date, that systemic treatments, mainly developed in developed countries, are effective in developing ones. For example, Love and colleagues [19] demonstrated the value of adjuvant tamoxifen and oophorectomy in Vietnam and fulvestrant appears equally active for advanced breast cancer in Japan and North America [20,21]. However, Richard Love wisely points out that therapies developed in high income societies may not always be directly transferred without evaluation of their effectiveness, including drug metabolism and cultural and psychosocial issues [9] and the operation of health care systems. Ragaz and colleagues [22] and this issue highlight that the introduction of early diagnosis and treatment has not only improved survival between provinces in Canada, but may be responsible for improved survival in urban Shanghai compared with rural China. 
Abbreviations

$\mathrm{BHGl}=$ Breast Health Global Initiative.

\section{Competing interests}

The author declares that he has no competing interests.

\section{Acknowledgements}

This article has been published as part of Breast Cancer Research Volume 12 Supplement 4, 2010: Controversies in Breast Cancer 2010. The full contents of the supplement are available online at http://breast-cancer-research.com/ supplements/12/S4

\section{Published: 20 December 2010}

\section{References}

1. Ferlay J, Shin HR, Bray F, Forman D, Mathers C, Parkin DM: Estimates of worldwide burden of cancer in 2008: GLOBOCAN 2008. Int J Cancer 2010 [Epub ahead of print].

2. Rastogi T, Hildesheim A, Sinha R: Opportunities for cancer epidemiology in developing countries. Nat Rev Cancer 2004, 4:909-917.

3. Igene $\mathrm{H}$ : Global health inequalities and breast cancer: an impending public health problem for developing countries. Breast J 2008, 14:428-434

4. Berry DA, Cronin KA, Plevritis S, Fryback DG, Clarke L, Zelen M, Mandelblatt JS, Yakovlev AY, Habbema JD, Feuer EJ: Effect of screening and adjuvant therapy on mortality from breast cancer. N Engl J Med 2005, 353:1784-1792.

5. Kalager M, Haldorsen T, Bretthauer M, Hoff G, Thoresen SO, Adami HO: Improved breast cancer survival following introduction of an organised mammography screening program among both screened and unscreened women: a population-based cohort study. Breast Cancer Res 2009, 11:R44

6. Blanks RG, Moss SM, McGahan CE, Quinn MJ, Babb PJ: Effect of NHS breast screening programme on mortality from breast cancer in England and Wales, 1990-8: comparison of observed with predicted mortality. BMJ 2000, 321:665-669.

7. Thomas DB, Gao DL, Ray RM, Wang WW, Allison CJ, Chen FL, Porter P, Hu YW, Zhao GL, Pan LD, Li W, Wu C, Coriaty Z, Evans I, Lin MG, Stalsberg H, Self SG: Randomised trial of breast self-examination in Shanghai: final results. J Natl Cancer Inst 2002, 94:1445-1457.

8. Yip CH, Smith RA, Anderson BO, Miller AB, Thomas DB, Ang ES, Caffarella RS, Corbex M, Kreps GL, MCTiernan A: Guideline implementation for breast healthcare in low and middle income countries: early detection resource allocation. Cancer 2008, 113:2244-2256.

9. Love RR: Defining a global research agenda for breast cancer. Cancer 2008, 113:2366-2371.

10. Barton $M B$, Frommer M, Shafiq J: Role of radiotherapy in cancer control in low-income and middle-income countries. Lancet Oncol 2006, 7:584-595.

11. Bese NS, Munshi A, Budrukkar A, Elzawawy A, Pervez CA: Breast radiation therapy guideline implementation in low and middle income countries. Cancer 2008, 113:2305-2314.

12. Eniu A, Carlson RW, El Saghir NS, Bines J, Bese NS, Vorobiof D, Masettie R,
Anderson BO: Guideline implementation for breast healthcare in low and middle income countries: treatment resource allocation. Cancer 2008 113:2269-2281.

13. Mendis S, Fukino K, Cameron A, Laing A, Fillipe A Jr, Khatib O, Leowski J, Ewen $\mathrm{M}$ : The availability and affordability of selected essential medicines for chronic diseases in six low and middle income countries. Bull World Health Organ 2007, 85:279-288.

14. Steinbrook R: Closing the affordability gap for drugs in low income countries. N Engl J Med 2007, 357:1996-1999.

15. Wong NS, Anderson BO, Khoo KS, Ang PT, Yip CH, Lu YS, Shao ZM, Pritchard Kl: Management of HER2-positive breast cancer in Asia: consensus statement from Asian Oncology Summit 2009. Lancet Oncol 2009, 10:1077-1085.

16. Bines J, Eniu A: Effective but cost-prohibitive drugs in breast cancer treatment: a clinician's perspective. Cancer 2008, 113:2353-2358.

17. Badwe RA, Hawaldar RW, Parmar V, Nadkarni M, Shet T, Desai S, Gupta S, Rakesh J, Vanmali V: Single injection depot progesterone prior to surgery and survival in women with operable breast cancer: a randomised controlled trial. Cancer Res 2009, 69 (24 Suppl):72.

18. Cuzick J, Dowsett M, Wale C, Salter J, Quinn E, Zabaglo L, Howell A, Buzdar A, Forbes JF: Prognostic value of a combined ER, PgR, Ki67, HER2 immunohistochemical (IHC4) score and comparison with the GHI recurrence score - results from TransATAC. Cancer Res 2009, 69 (24 Suppl):74.

19. Love RR, Duc NB, Allred DC, Binh NC, Kha NN, Thuan TV, Mohsin SK, Roanh le D, Khang HX, Tran TL, Quy TT, Thuy NV, The PN, Cau TT, Tung ND, Huong DT, Quang le M, Hien NN, Thuong L, Shen TZ, Xin Y, Zhang Q, Havighurst TC, Yang YF, Hillner BE, DeMets DL: Oophorectomy and tamoxifen adjuvant therapy in premenopausal Vietnamese and Chinese women with operable breast cancer. J Clin Oncol 2002, 20:2559-2566.

20. Ohno S, Rai Y, Iwata H, Yamamoto N, Yoshida M, Iwase H, Masuda N, Nakamura S, Taniguchi H, Kamigaki S, Noguchi S: Three dose regimens of fulvestrant in postmenopausal Japanese women with advanced breast cancer: results from a double-blind, phase II comparative study (FINDER1). Ann Oncol 2010 [Epub ahead of print].

21. Pritchard KI, Rolski J, Papai Z, Mauriac L, Cardoso F, Chang J, Panasci L, lanuli C, Kahan Z, Fukase K, Lindermann JP, Macpherson MP, Neven P: Results of a phase II study comparing three dosing regimens of fulvestrant in postmenopausal women with advanced breast cancer (FINDER2). Breast Cancer Res Treat 2010 [Epub ahead of print].

22. Ragaz J, Wong H: Comparative analysis of breast cancer $(\mathrm{BrCa})$ mortality reduction among regions of Canada between 1950-2004: impact of systemic and diagnostic guidelines after 1977 with a model definition of number of potentially avoided annual deaths (N-PAAD). Cancer Res 2009, 69 (24 Suppl):2063.

doi:10.1186/bcr2739

Cite this article as: Howell A: The emerging breast cancer epidemic: early diagnosis and treatment. Breast Cancer Research 2010, 12(Suppl 4):S10. 